Vol 2 No 3 August-October 2019. pp.57-66. Journal PUBLICUHO Faculty of Social and Political Sciences Halu Oleo University, Kendari, Southeast Sulawesi, Indonesia. ISSN 2621-1351 (online), ISSN 2685-0729 (print) Open Access at:

http://ojs.uho.ac.id/index.php/PUBLICUHO/index

\title{
NILAI SOSIAL DAN TUJUAN HAROA PADA ACARA SYUKURAN MASYARAKAT MUNA DI DESA LIABALANO
}

\author{
${ }^{1}$ La Ode Monto Bauto, ${ }^{2}$ Wa Ode Nisma \\ 1,2,Fakultas IImu Sosial dan IImu Politik, Universitas Halu Oleo \\ laodemonto@yahoo.co.id
}

\begin{abstract}
Based on the phenomenon that occurred in Muna, he recognized one of the traditions of the Haroa culture every thanksgiving event. This study aims to determine and understand the social values and objectives of haroa at the Muna community thanksgiving event. The research method used is using qualitative research methods. The research method using a qualitative descriptive method is a research method that produces a narrative description of the procedures for implementing the haroa event that can be observed. The research technique used, namely by means of observation, interviews, and documentation. The informants in the study were 14 people in the community. Sources of data in this study, namely primary data and secondary data. The data analysis technique is that the researcher collects all the data obtained both from the results of observations, interviews and documentation, then the researcher sorts and selects the most accurate data about the focus of the related research. Then the researchers performed data processing to find other information related to the phenomenon of the social and cultural life of the Muna community. The results of the study showed that the social values of haroa in Muna society contained three socio-cultural values in the haroa culture, namely; the first is the value of solidarity, the two values of cooperation, and the third is the value of trust. While the purpose of haroa in the Muna community is as a form or manifestation of gratitude to Allah SWT, as a form of refusing reinforcements and for commemorating Islamic holidays.
\end{abstract}

\section{Keywords: Haroa; Social Value; Value}

\begin{abstract}
Abstrak
Berdasarkan fenomena yang terjadi pada Muna mengenal salah satu tradisi budaya haroa setiap acara syukuran. Penelitian ini bertujuan untuk mengetahui dan memahami nilai sosial dan tujuan haroa pada acara syukuran masyarakat Muna Metode penelitian yang digunakan yakni menggunakan metode penelitian kualitatif. Metode penelitian menggunakan metode kualitatif deskriptif adalah metode penelitian yang menghasilkan narasi uraian tentang tata cara pelaksanaan acara haroa orang yang dapat diamati. Teknik penelitian yang digunakan, yaitu dengan cara observasi, wawancara, dan dokumentasi. Adapun informan dalam penelitian adalah warga masyarakat 14 orang. Sumber data dalam penelitian ini, yaitu data primer dan data sekunder. Adapun teknik analisis data yakni peneliti mengumpulkan seluruh data yang diperoleh baik dari hasil observasi, wawancara maupun dokumentasi, kemudian peneliti memilah dan memilih hasil data yang paling akurat mengenai fokus penelitian yang terkait. Kemudian peneliti melakukan pengolahan data untuk mencari informasi lain yang berkaitan dengan fenemonena kehidupan sosial budaya masyarakat Muna. Hasil penelitian yang diperoleh bahwa nilai sosial haroa pada masyarakat Muna terdapat tiga nilai sosial budaya dalam budaya haroa, yaitu; pertama nilai solidaritas, kedua nilai kerjasama, dan ketiga nilai kepercayaan. Sedangkan tujuan haroa pada masyarakat Muna adalah sebagai bentuk atau wujud rasa syukur kepada Allah SWT, sebagai bentuk tolak bala dan untuk memperingati hari-hari besar Islam.
\end{abstract}

Kata Kunci: Haroa; Nilai; Nilai Sosial 


\section{PENDAHULUAN}

Bangsa Indonesia memiliki kekayaan alam dan budaya yang beraneka ragam tersebar dari Sabang sampai Merauke, Pulau Miangas sampai Pulau Rote.. Kekayaan yang dimiliki oleh masyarakat Indonesia bukan hanya kekayaan sumber daya alam saja, melainkan juga Indonesia memiliki kekayaan lain seperti kekayaan kebudayaan suku bangsa. Indonesia terdiri atas berbagai suku yang memiliki keanekaragaman tradisi budaya. Keanekaragaman tradisi merupakan salah satu aspek budaya bangsa, yang harus dilindungi dan dilestarikan. Berbagai suku bangsa di Indonesia yang berjumlah 714 etnik suku bangsa memiliki keragaman bahasa, agama, adat istiadat dan tradisi budaya yang berbeda-beda. Indonesia merupakan negara kepulauan yang penuh dengan kekayaan serta keragaman budaya, ras, suku bangsa, kepercayaan, agama, bahasa daerah, dan masih banyak lainnya.Meskipun penuh dengan keragaman budaya, Indonesia tetap satu sesuai dengan semboyannya, Bhineka Tunggal Ika yang artinya"Meskipun berbeda-beda tetapi tetap satu jua". Keragaman budaya turut serta didukung oleh wilayah Negara Kesatuan Republik Indonesia yang terpisah wilayah-wilayahnya oleh lautan.

Masyarakat Indonesia mengembangkan budaya secara turun temurun karena budaya merupakan warisan yang paling berharga, sehingga keberadaan budaya tidak pernah punah karena sejak awal hingga sekarang budaya itu tetap dilestarikan oleh anak bangsa. Keragaman merupakan suatu kondisi pada kehidupan masyarakat. Perbedaan seperti itu ada pada suku bangsa, agama, ras, serta budaya. Keragaman yang ada di Indonesia adalah kekayaan dan keindahan bangsa indonesia. Pemerintah harus bisa mendorong keberagaman tersebut menjadi suatu kekuatan untuk bisa mewujudkan persatuan dan kesatuan nasional menuju Indonesia yang lebih baik.

Keberagaman bangsa Indonesia dibentuk oleh banyaknya jumlah suku bangsa yang tinggal di wilayah Indonesia dan tersebar di berbagai pulau dan wilayah di penjuru Indonesia. Setiap suku bangsa memiliki ciri khas dan karakteristik sendiri pada aspek sosial dan budaya. Menurut penelitian badan pusat statistik (BPS), yang dilakukan tahun 2010, di Indonesia terdapat 1.128 suku bangsa. Keberagaman yang ada pada masyarakat bisa menjadi kekayaan bangsa Indonesia dan potensi bangsa. Keberagaman juga menjadi tantangan, hal itu disebabkan karena orang yang mempunyai perbedaan pendapat bisa lepas kendali. Munculnya perasaan kedaerahan serta kesukuan yang berlebihan dan dibarengi tindakan yang dapat merusak persatuan, hal tersebut dapat mengancam keutuhan Negara KesatuanRepublik Indonesia (NKRI). Karena itu adanya usaha untuk dapat mewujudkan kerukunan bisa dilakukan dengan menggunakan dialog dan kerjasama dengan prinsip kesetaraan, kebersamaan, toleransidan juga saling menghormati satu sama lain (BPS Indonesia, 2010). Kebudayaan disetiap daerah tentunya berbeda-beda, salah satu kebudayaan yang ada dimasyarakat Sulawesi Tenggara, tepatnya di Kabupaten Muna yang masih dilestarikan sampai saat ini yaitu haroa.Keberadaan haroa pada masyarakat Muna sudah ada sejak lama, semenjak kerajaan Muna dipimpin oleh Raja Muna La Ode Abdul Rahman (Sangia 
Vol 2 No 3 August-October 2019. pp.57-66. Journal PUBLICUHO Faculty of Social and Political Sciences Halu Oleo University, Kendari, Southeast Sulawesi, Indonesia. ISSN 2621-1351 (online), ISSN 2685-0729 (print) Open Access at:

http://ojs.uho.ac.id/index.php/PUBLICUHO/index

Latugho) dan bertahan hingga sekarang. Haroa dalam masyarakat Muna khususnya di Desa Libalano masih ada hingga sekarang karena kegiatan adat istiadat tradisional masyaraat Muna selalu diawali dan diakhiri dengan kegiatan baca haroa sebelum acara makan bersama Haroa ini dilakukan karena adanya urusan hidup (mangkano nesuana) atau jalan kanan dan pengurusan orang yang meningggal dunia (mangkano kema) jalan kiri.

Haroa dapat diartikan sebagai makanan yang beraneka ragam yang dikemas sedemikian rupa dalam suatu wadah dan dibaca-baca oleh Lebe (Modin atau modhi, Khatib atau hatibi dan Imam atau imamu).Haroa merupakan tradisi turun temurun dari nenek moyang dan biasa dilakukan pada waktu-waktu tertentu. Misalnya, pada hari-hari besar Islam seperti hari raya Idul fitri, Idul adha, dan acara adat pernikahan, katoba (pengislaman), kampua (aqikah), kariya (pingitan), memasuki rumah baru dan pada hari kematian.

Tradisi haroa erat kaitannya dengan system kepercayaan religi dan merupakan suatu bentuk dalam meningkatkan hubungan silahturahmi antar keluarga, mempererat hubungan tetangga, dan masyarakat untuk menjalin hubungan vertical kepada leluhur dan terhadap Tuhan Yang Maha Esa. Dalam tradisi haroa mengandung nilai kekelvargaan yang diyakini dapat mengikat kembali atau mempererat hubungan silahturahmi, dan dapat mempengaruhi tatanan kehidupan social ekonomi masyarakat seperti, kebersamaan, kekelvargaan dalam masyarakat.

Pelaksanaan haroadalam acara syukuran dipimpin oleh modin (modhi), Khatib (hatibi,) dan Imam (imamu) diawali dengan membakar dupa atau kemenyan, selanjutnya mengucapkan syahadat dan istighfar, kemudian membaca beberapa ayat suci Al-Qur'an, dilanjutkan dengan membaca tasbih, tahmid, tahlil dan takbir sebanyak 100 kali. Setelah itu dilanjutkan membaca do'a selamat, do'a tolak bala, do'a kemudahan rezeki, dan do'a pengampunan dosa untuk keluarga yang telah meninggal dunia. Selanjutnya diakhiri dengan menjabat tangan orang yang memimpin haroa, lalu saling berjabat tangan dengan semua anggota keluarga yang hadir. Setelah itu dilanjutkan dengan makan bersama.

Budaya haroa masih eksis hingga saat ini karena haroa merupakan tradisi nenek moyang orang Muna sejak zaman dulu, haroa dapat dijadikan sebagai lading ekonomi bagi tokoh agama atau tokoh adat atau Lebe (Imam, Khatib, dan Modhi), haroa masih eksis karena kurangnya pemahaman nilai agama. Pelaksanaan atau kegiatan haroa yang dilakukan pada acara syukuran masyarakat Muna memiliki tujuand an nilai sosial. Berdasarkan hal inilah penulis tertarik untuk meneliti lebih lanjut tentang kebudayaan yang terbentuk dalam kehidupan masyarakat Muna.

Berdasarkan latar belakang, maka rumusan masalah yang di kaji adalah Apa nilai sosial haroa pada acara syukuran masyarakat Muna di Desa Liabalano Kecamatan Kontunaga Kabupaten Muna ? dan apa tujuan haroa pada acara syukuran masyarakat Muna di Desa Liabalano Kecamatan Kontunaga Kabupaten Muna? 


\section{METODE PENELITIAN}

Pemilihan informan dalam penelitian ini menggunakan cara purposive sampling yakni memilih informan secara sengaja yang diangggap memiliki pengetahuan tentang haroa, yaitu masyarakat dan tokoh masyarakat yang berada di Desa Liabalano Kecamatan Kontunaga Kabupaten Muna sebanyak 14 orang. Subjek penelitian adalah pihak-pihak yang dijadikan sebagai sampel dalam sebuah penelitian. Subjek penelitian dalam penelitian ini adalah masyarakat dan tokoh masyarakat yang berada di lokasi penelitian.

Jenis data yang digunakan daam penelitian ini, yaitu data kualitatif. Data kualitatif merupakan data yang tidak dapat dinominasikan dengan menggunakan angka tetapi lebih menekankan pada aspek pemahaman secara mendalam terhadap suatu masalah daripada melihat permasalahan untuk penelitian generalisasi seperti memberikan gambaran penjelasan dan uraian dalam bentuk narasi untuk mendeskripsikan terkait dengan masalah yang akan diteliti.

Sumber data yaitu data primer dan data sekunder. Data primer yaitu data yang diperoleh langsung dari sejumlah informan melalui tahap observasi, wawancara dan dokumentasi mengenai nilai sosial dan tujuan haroa. Data Sekunder, yakni data yang diperoleh melalui penelusuran sebagai literature ilmiah data hasil penelitian yang relevan data yang diterbitkan oleh instansi terkait dan informasi dari sejumlah informan. Selain itu digunakan triangulasi yang digunakan adalah triangulasi sumber. Triangulasi sumber digunakkan untuk menguji kredibilitas data yang dilakukan dengan cara mengecek data yang telah diperoleh melalui beberapa sumber. Tujuan dari teknik triangulasi data bukan untuk mencari kebenaran tentang beberapa fenomena tetapi lebih pada peningkatan pemahaman peneliti terhadap apa yang ditemukan. Triangulasi sumber dalam penelitian ini dilakukan dengan membandingkan data yang diperoleh melalui wawancara, observasi dan dokumentasi. (Miles dan Huberman, 1992)

\section{HASIL DAN PEMBAHASAN}

\section{Nilai Sosial Haroa}

Nilai dalam bahasa Inggris disebut juga value yang berasal dari bahasa latin yaitu valere yang berarti berguna, mampu, berdaya, berlaku, dan kuat. Nilai adalah sifat-sifat atau (halhal) yang penting atau berguna bagi kemanusiaan. Dalam pengertian abstrak, bahwa nilai itu tidak dapat ditangkap oleh panca indra, yang dapat dilihat adalah objek yang mempunyai nilai atau tingkah laku yang mengandung nilai. Nilai merupakan sesuatu yang dihargai, selalu dijunjung tinggi, serta dikejar oleh manusia untuk memperoleh kebahagiaan hidup. Manusia dapat merasakan kepuasan dengan nilai. Nilai merupakan sesuatu yang abstrak tetapi secara fungsional mempunyai ciri yang dapat membedakan satu dengan yang lainnya (Gusal, $2015: 3$ ).

Nilai adalah sebagai sesuatu yang dimiliki oleh seseorang dan sebagai sesuatu yang berkaitan dengan objek. Nilai adalah sesuatu yang ada dalam diri manusia, sesuatu yang ia 
Vol 2 No 3 August-October 2019. pp.57-66. Journal PUBLICUHO Faculty of Social and Political Sciences Halu Oleo University, Kendari, Southeast Sulawesi, Indonesia. ISSN 2621-1351 (online), ISSN 2685-0729 (print) Open Access at: http://ojs.uho.ac.id/index.php/PUBLICUHO/index

berikan atau dijadikan ukuran baku bagi persepsinya mengenai dunia luar. Nilai merupakan suatu konsep, yaitu hasil pembentukan mental yang dirumuskan dari tingkah laku manusia sehingga menjadi anggapan yang hakiki baik dan perlu dihagai sebagaimana mestinya. Secara ekstrim nilai adalah sesuatu yang dimiliki hanya oleh manusia dan manusialah yang memberikan atau menilai dunia luarnya, yang pada dasarnya tidak bernilai (Sudarma. M., $2008: 35)$.

Niai sosial adalah penghargaan yang diberikan masyarakat kepada segala sesuatu yang terbukti memiliki daya guna fungsional bagi kehidupan bersama. Fungsi nilai sosial, yaitu sebagai faktor pendorong, sebagai petunjuk arah dan sebagai bentuk perlindungan (Waluya, 2007:)

Nilai sosial memiliki ciri-ciri nilai sosial diantaranya, yaitu bisa memengaruhi pengembangan diri sosial; Mempunyai pengaruh yang beragam antar warga masyarakat; Cenderung berkaitan satu dengan yang lain; Terbentuk melalui sosialisasi atau proses belajar; Merupakan bagian dari usaha pemenuhan kebutuhan dan kepuasan sosial manusia; Merupakan konstruksi masyarakat sebagian hasil interaksi antar warga masyarakat; Disebarkan diantara warga masyarakat bukan bawaan sejak lahir; Bervariasi antara kebudayaan yang satu dengan kebudayaan yang lain.

Nilai sosial dalam masyarakat bersumber dari tiga hal, yaitu pertama bersumber dari Tuhan (nilai theonom). Kedua, nilai yang bersumber dari masyarakat (nilai heteronom) dan ketiga, nilai yang bersumber dari individu (nilai otonom). Nilai sosial mempunyai fungsi tertentu dalam masyarakat, yaitu sebagai media pegawas dengan daya tekan dan daya ikat nilai bisa menuntun bahkan bisa menekan manusia intuk berbuat baik dalam kehidupan bermasyarakat; Penentu akhir bagi orang atau grup dalam memenuhi peran sosialnya dikehidupan bermasyarakat; Sebagai alat solidaritas bagi anggota-anggota kelompok dalam masyarakat; menyumbangkan seperangkat alat yang bisa digunakan untuk menetapakan derajat sosial dari orang atau perorangan atau grup di kehidupan masyarakat.

Peran nilai sosial dalam kehidupan bermasyarakat, yaitu sebagai petunjuk arah dalam bersikap atau bertindak; sebagai acuan dan sumber motivasi untuk melakukan sesuatu; mengarahkan masyarakat untuk berperilaku sesuai dengan nilai yang berlaku dilingkungannya; Pendorong, pengawas, dan penekan individu untuk berbuat baik; Alat solidaritas untuk mendorong kerjasama masyarakat sehingga dapat meraih tujuan yang tidak bisa dicapai sendiri (Anonim, 2019).

Solidaritas secara epistemologi adalah sifat suatu rasa (senasib) atau perasaan setia kawan. Jadi, solidaritas dapat diartikan sebagai kesediaan untuk memperhatikan kepentingan dan bekerja sama dengan orang lain. Solidaritas ini merupakan perekat bagi para pendukung demokrasi agar tidak jatuh kedalam perpecahan akibat terlalu mengutamakan kepentingan pribadi tanpa mengingat adanya persamaan hak maupun 
semangat kebersamaan. Hal ini menunjukkan adanya prinsip solidaritas, sebab walau berbeda pandangan atau kepentingan, para pihak tetap sepakat untuk mempertahankan kesatuan/ikatan bersama. Nilai solidaritas mengikat manusia yang sama-sama memiliki kebebasan untuk mempertimbangkan kepentingan pihak lain. Nilai solidaritas dapat menumbuhkan sikap batin dan kehendak unttuk mendapatkan kebaikan bersama diatas kepentingan pribadi, mengasihi sesama dan murah hati terhadap sesama warga masyarakat. Dengan tumbuhnya sikap tersebut, perasaan saling melindungi dan menjaga satu sama lain akan terwujud sehingga tercipta kedamaian (Hamidi J. dan Mustafa, 2010).

Kerjasama menurut Suit (1996:68) adalah suatu upaya untuk menghimpun kekuatan guna menyeelesaikan pekerjaan berat dan besar yang tidak dapat diselesaikan oleh satu orang. Kerjasama sangat bermanfaat dan dibutuhkan untuk memecahkan berbagai masalah teknis pekerjaan dan berbagai masalah intens organiasi. Selain itu, kerjasama juga dapat meningkatkan pelayanan terhadap relasi atau pelanggan yang dapat digunakan sebagai banteng pertahanan dalam menghadapi persaingan. Kerjasama Menurut Pamudji (1985:12) adalah mengindikasikan adanya dua pihak atau lebih yang berinteraksi secara dinamis untuk mencapai suatu tujuan bersama. Sedangkan menurut Abdulsyani (2012) kerjasama adalah bentuk proses sosial, dimana didalamnya terdapat aktivitas tertentu yang ditujukan untuk mencapai tujuan bersama dengan saling membantu dan saling memahami terhadap aktivitas masing-masing (Sahban M, 2018:113)

Nilai adalah sesuatu yang diyakini kebenarannya dan dianut serta dijadikan sebagai acuan dasar individu dan masyarakat dalam berperilaku yang dipandang baik, benar, bernilai maupun berharga. Kepercayaan adalah suatu hal yang menjadi dasar pandangan hidup manusia yakni sebuah pemikiran yang mendasar dan mendalam terhadap suatu hal yang kemudian di anut untuk menjadi pedoman hidup mereka. Jadi nilai kepercayaan adalah nilai yang menjadi dasar pandangan hidup manusia yakni sebuah pemikiran yang mendasar dan mendalam terhadap suatu hal yang kemudian di anut untuk menjadi pedoman hidup (Allegra, 2017).

Haroa dalam tradisi masyarakat suku Muna adalah makanan yang beraneka ragam yang dikemas sedemikian rupa dalam suatu wadah dan dibaca-baca oleh lebe. Haroa terdiri dari beberapa macam, yaitu haroa rasulu, haroa ssumanga, haroano radhabu, haroa turuntana, haroa nisifu, haroa alono sangia, dan haroa nomoalono. Haroa Rasulu, yaitu haroa yang dibaca pada waaku peringatan maludhu (maulid) Nabi Muhammad SAW pada malam 12 rabi'ulawal. Haroa sumanga, yaitu haroa yang dibaca pada waktu orang sembuh dari sakit yang diduga mendapat kasundu (siksaan) dari roh orang yang telah meninggal dunia yang memiliki hubungan keluarga dengannya. Haroano radhabu, yaitu haroa yang dibaca pada awal bulan rajab sebagai doa untuk meminta perlindugan dan keselamatan dari Allah SWT. Haroa turuntana (haroa turun tanah) yaitu haroa yang dibaca pada waktu pulang menyiram kuburannya orang yang baru meninggal. Haroa nisifu, yaitu haroa yang dibaca pada pertengahan bulan syaban. Haroa alono sangia (malam keramat/mulia yaitu haroa 
Vol 2 No 3 August-October 2019. pp.57-66. Journal PUBLICUHO Faculty of Social and Political Sciences Halu Oleo University, Kendari, Southeast Sulawesi, Indonesia. ISSN 2621-1351 (online), ISSN 2685-0729 (print) Open Access at:

http://ojs.uho.ac.id/index.php/PUBLICUHO/index

yang dibaca pada malam tertentu dibulan ramadhan dan bulan syawal. Haroa nomoalono (enam malam), yaitu haroa yang dilakukan setelah enam hari lebaran idul fitri. (La Sanya $2018: 82-94)$.

Haroamerupakan tradisi dan rumpun mediatradiosional yang merupakan salah satu media dakwah efektif yang digunakan oleh tokoh agama (khatibi, lebe) untuk menyampaikan pesan-pesan dakwah. Pendekatan denganmedia "Haroa" adalah salah satu yang dianggap paling efektif dalam menyampaikan pesan-pesan dakwah Islam bagi masyarakat yang mendiami pesisir pantai Pulau Buton.Haroa juga dianggap sebagai media pengenalan dan penanaman nilai-nilai moral agama Islam, digunakan oleh tokoh-tokoh agama lebe, mokimu, moji, khatibi untuk memperkenalkan nilai-nilai ajaran agama Islam kepada sanak keluarga dan handai taulan. Melalui haroa, masyarakat dapat mengetahui pengtingnya merayakan hari-hari besar agama Islam seperti maulidan, isra mi'raj dan sebagainya. Melalui haroa ini pula umat muslim dijelaskan ibadah-ibadah yang wajib dikerjakan dan hal-hal yang bersifat tradisi tetapi terkadang masyarakat justru "tradisi" tersebut dianggap sebagai yang "wajib" dan meninggalkan perintah yang wajib. (Nurdin, 2013 : 105-106).

Haroa adalah ritual perayaan hari-hari besar Islam. Pelaksanaannya dilaksanakan di rumah-rumah warga yang diikuti semua anggota rumah dan tetangga yang diundang baik yang berbeda suku maupun agama. Mereka duduk mengumpul di satu ruangan, dan di tengahnya ada nampan yang berisikan kue-kue seperti onde-onde, cucur (cucuru), bolu, baruasa (kue beras), ngkaowi-owi (ubi goreng), dan sanggara (pisang goreng). Semua kue tersebut mengelilingi piring yang berisikan nasi dan di atasnya ada telur goreng. Usai pembacaan doa, acara selanjutnya adalah makan-makan. (Mahrudin, 2009 : 1456).

Berdasarkan penelitian yang telah peneliti lakukan di lokasi penelitian ada tiga nilai sosial yang terdapat dalam haroa pada acara syukuran masyarakat Muna di Desa Liabalano Kecamatan Kontunaga Kabupaten Muna, yaitu nilai solidaritas, nilai kerja sama dan nilai kepercayaan.

1) Nilai solidaritas yaitu nilai yang mengandung integrasi, tingkat dan jenis intergrasi di tunjukan oleh masyarakat atau kelompok orang berupa kesepakatan bersama, gotong royong, saling membantu dan menolong;

2) Nilai kerjasama, yaitu usaha yang dilakukan bersama-sama atau saling membantu antara dua atau beberapa pihak;

3) Nilai kepercayaan, yaitu nilai yang menjadi dasar pandangan hidup manusia yakni sebuah pemikiran yang mendasar dan mendalam terhadap kebudayaan.

\section{Tujuan Haroa}

Tradisi haroa atau dalam masyarakat Muna sering menyebutnya "baca-baca" merupakan tradisi religius masyarakat Muna yang telah dipraktekkan sejak lama. Konon 
katanya, tradisi ini diperkenalkan pertama kali saat Kerajaan Wuna dipimpin oleh Raja Muna yang bernama La Ode Abdul Rahman (Sangia Latugho). Sangia Latugho mendapatkan ajaran Islam dari Saidi Rabba seorang Arab yang menyebarkan Islam di Muna. Haroa biasa dilakukan masyarakat sebagai bentuk atau wujud rasa syukur kepada Allah, tolak bala (menghindari mara bahaya) dan untuk merayakan hari-hari besar Islam (Rahman, 2017)

Syukur merupakan rasa takjub, penuh rasa terimakasih, penghargaan terhadap nikmat kehidupan. Rasa syukur mendorong setiap individu untuk melakukan suatu perbuatan baik, yang nanti berhubungan atau berkorelasi positif dengan peningkatan sikap altruistik terhadap orang lain. Ini karena, berbagi kebaikan atau kenikmatan adalah wujud nyata dari rasa syukur yang menjadi langkah penting bagi seseorang untuk menjadi pribadi yang berguna bagi siapapun di dunia ini. Konsep syukur memang selalu beriringan dengan konsep sabar yang memberikan pilihan kepada setiap umat untuk menghadapi semua cobaab dan nikmat Allah dengan penuh kelapangan, menerima apa adanya, dan tentu harus bersikap tawakal dengan semua ketentuan Allah. Dalam kehidupan masyarakat Indonesia, perilaku syukur sesungguhnya sudah sangat mengakar kuat, yakni dengan adanya tradisi syukuran yang sering dilakukan delam bentuk doa bersama, sujud syukur dan bersedekah kepada orang-orang yang tidak mampu (Takdir Mohammad, 2018: 28)

Syukuran memiliki dua pengertian. Yaitu; Syukuran berasal dari kata dasar syukur. Syukuran adalah sebuah homonim karena arti-artinya memiliki ejaan dan pelafalan yang sama tetapi maknanya berbeda. Syukuran memiliki arti dalam kelasnomina atau kata benda sehingga syukuran dapat menyatakan nama dari seseorang, tempat, atau semua benda dan segala yang dibendakan danverba atau kata kerja sehingga syukuran dapat menyatakan suatu tindakan, keberadaan, pengalaman, atau pengertian dinamis lainnya. Syukuran berarti mengadakan selamatan untuk bersyukur kepada Tuhan (karena terhindar dari maut, sembuh dari penyakit, dan sebagainya) (Anonim, 2019).

Tolak bala (menghindari marabahaya) berarti penangkal bencana (bahaya, penyakit, dan sebagainya) dengan mantra (kenduri dan sebagainya). Tolak bala biasanya dilakukan untuk menghindari bala atau menangkal bala seperti kecelakaan atau musibah yang akan menanti kita dikemudian hari (Anonim, 2019).

Hari besar Islam, yaitu merupakan hari yang penting bagi umat Islam. Dimana, dalam Islam sudah ditetapkan hari, bulan dan malam-malam yang dimana doa akan dikabulkan. Seluruhnya mempunyai hikmah yang besar. Begitu juga Allah SWT akan memberikan kesempatan dan memaafkan Umat-Nya melalui perantara-perantara hari dan waktu yang sudah ditetapkan. Hal tersebut diupayakan agar perasaan seorang yang beriman diketuk dan dimotivasi agar selalu meraih dan melakukan kebaikan (Anonim, 2019).

Berdasarkan penelitian yang telah peneliti lakukan di lokasi penelitin ada tiga tujuan haroa yang terdapat dalam haroa pada acara syukuran masyarakat Muna di Desa Liabalano Kecamatan Kontunaga Kabupaten Muna, yaitu bentuk atau wujud rasa syukur kepada Allah, kedua tolak bala, dan ketiga merayakan hari besar Islam. 
Vol 2 No 3 August-October 2019. pp.57-66. Journal PUBLICUHO Faculty of Social and Political Sciences Halu Oleo University, Kendari, Southeast Sulawesi, Indonesia. ISSN 2621-1351 (online), ISSN 2685-0729 (print) Open Access at: http://ojs.uho.ac.id/index.php/PUBLICUHO/index

1) Bentuk atau wujud rasa syukur kepada Allah atas limpahan rezeki yang kita dapat, misalnya ada anak (kerabat dekat) yang lulus jadi tentara maupun PNS, karena diberikan kesehatan, diberikan kesempatan untuk bertemu sanak saudara yang jauh;

2) Tujuanharoa sebagai tolak bala misalnya jika ada anak atau keluarga yang akan bekerja jauh atau bepergian jauh maka harus diadakan haroa untuk menghindari balaa yang mungkin menghampirinya ditempat ia pergi bekerja;

3) Merayakan hari-hari besar Islam seperti memperingati Maulid Nabi, Muhammad SAW. menyambut kedatangan bulan suci ramadhan, menyambut malam turunnya Alqur'an, menyambut malam Lailatul Qodar, merayakan Isra Mi.raj Nabi Muhammad SAW. merayakan hari raya Idul Fitri dan Idul Adha.

\section{KESIMPULAN}

Berdasarkan hasil dan pembahasan, kesimpulan dari penelitian ini adalah:

1. Nilai sosial yang terdapat dalam budaya haroa pada acara syukuran masyarakat Muna di Desa Liabalano Kecamatan Kontunaga Kabupaten Muna, ada tiga (3), yaitu nilai solidaritas, nilai kerja sama dan nilai kepercayaan. Nilai solidaritas yaitu nilai yang mengandung integrasi, tingkat dan jenis intergrasi di tunjukan oleh masyarakat atau kelompok orang berupa kesepakatan bersama, gotong royong, saling membantu dan menolong; Nilai kerjasama, yaitu usaha yang dilakukan bersama-sama atau saling membantu antara dua atau beberapa pihak; Nilai kepercayaan, yaitu nilai yang menjadi dasar pandangan hidup manusia yakni sebuah pemikiran yang mendasar dan mendalam terhadap suatu hal yang kemudian di anut untuk menjadi pedoman hidup.

2. Tujuan haroa pada acara syukuran masyarakat Muna di Desa Liabalano Kecamatan Kontunaga Kabupaten Muna ada tiga, yaitu bentuk atau wujud rasa syukur kepada Allah, kedua tolak bala, dan ketiga merayakan hari besar Islam. Bentuk atau wujud rasa syukur kepada Allah atas limpahan rezeki yang kita dapat, misalnya ada anak (kerabat dekat) yang lulus jadi tentara maupun PNS, karena diberikan kesehatan, diberikan kesempatan untuk bertemu sanak saudara yang jauh; Tujuanharoa juga dianggap sebagai tolak bala misalnya jika ada anak atau keluarga yang akan bekerja jauh atau bepergian jauh maka harus diadakan haroa untuk menghindari bala yang mungkin menghampirinya ditempat ia pergi bekerja; Merayakan hari besar Islam seperti memperingati maulid Nabi, menyambut kedatangan bulan suci ramadhan, menyambut malam turunnya al-qur'an, menyambut malam lailatul qodar, merayakan hari raya Id dan sebagainya. 


\section{DAFTAR PUSTAKA}

Allegra, 2017. Nilai Kepercayaan. https://Brainly.Co.Id/Tugas/10006074

Anonim, 2019. Hari-hari Penting Islam https://www.trt.net.tr/melayu/program /2016/05/28/jelaskan-islam-kepadaku-18-hari-penting-dalam-islam499588

Anonim, 2019. Maksud dan Arti Kata Syukuran Berdasarkan KBBI dan berbagai Sumber. Dikutip dari https://www.apaarti.com/syukuran.html

Anonim, 2019. Apa Arti Tolak Bala. https://www.apaarti.com/tolak-bala.html

Anonim, 2019. Arti Kata Haroa Makna Pengertian Dan Definisi Dari Kata Haroa. Dikutip dari https://www.apaarti.com/haroa.html

BPS 2010.Suku Bangsa di Indonesia. Dikutip dari https://id.m.wikipedia.id

Gusal La ode, 2015. Nilai-Nilai Pendidikan dalam Cerita Rakyat Sulawesi Tenggara Karya La Ode Sidu. Jurnal Huanka. Vol 3, No. 17

Hamidi J. dan Mustafa, 2010. Civic Education: Antara Realitas Politik dan Hukumnya. Jakarta: Gramedia Pustaka Utama

Mahrudin, 2009. Haroa Masyarakat Islam Buton Sebagai Media Resolusi Konflik Dalam Menciptakan Perdamaian Umat Sekaligus Media Integrasi Antara Suku Bangsa. Conference Proccedings, AICIS XII

Miles dan Huberman, 1992.Analisis Data Kualitatif: Buku Sumber tentang Metode-Metode Baru. Jakarta: UI Press

Nurdin, 2015. TRADISI HAROA (Dakwah Islam Dalam Masyarakat Marginal Muslim Buton). Jurnal Dakwah, Vol. XVI, No. 1

Rahman La Ode, 2017.Tradisi Haroa, Tradisi Religius Masyarakat Muna. Dikutip dari https://munabangkit.com/tradisi-haroa-masyarakat-muna/

Sahban M. 2018. Kolaborasi Pembangunan Ekonomi di Negara Berkembang. Makassar: CV Sah Media

Sanya La., 2018. Adat Istiadat Suku Muna dalam Pandangan Islam Adhati Nemoneaghono Mieno Wuna Welofetilani Islam. Makassar :CV Inti Mediatama

Sudarma M. 2008. Sosiologi untuk Kesehatan. Jakarta: Salemba Medika

Takdir Mohammad, 2018. Psikologi Syukur: Perspektif Psikologi Qurani dan Psikologi Positif untuk Menggapai Kebahagiaan Sejati (Authentic Happiness). Jakarta: PT Elex Media Komputindo

Waluya. B, 2007. Sosioliogi: Menyelami Fenomena Sosial di Masyarakat. Bandung: PT Setia Purna Inves 